International Journal of Translational

Medical Research and Public Health | 2022 | Volume 6 | Issue I | e395

\begin{tabular}{|c|c|c|}
\hline & & $\begin{array}{l}\text { INTERNATIONAL JOURNAL OF TRANSLATIONAL } \\
\text { MEDICAL RESEARCH AND PUBLIC HEALTH } \\
\text { ISSN: } 2576-9499 \text { (Online) }\end{array}$ \\
\hline ITTMRPH & Available online at www.ijtmrph.org & $\begin{array}{l}\text { ISSN: } 2576-9502 \text { (Print) } \\
\text { DOI: 10.2 I 106/ijtmrph.395 }\end{array}$ \\
\hline
\end{tabular}

\title{
FIELD REPORT | WATER AND SANITATION \\ Individual and Community Level Factors Related to Sanitation, Water Quality, Treatment and Management in Rural Communities in Accra, Ghana: A Field Study Report
}

\author{
Angelique B.Willis, BSPH'; Mildred Addo, BA²; Lauren E. Yoder, AS'; Cassandra K. Johnson, AS'; \\ Sydney L. Resler, BA'; Leticia J.Young'; Elizabeth Armstrong-Mensah, $\mathrm{PhD}^{\circledR}$ \\ 'Georgia State University, Atlanta, GA 30303, United States of America; ${ }^{2}$ Community Water and Sanitation Agency, Greater Accra, Regional Office, Ghana. \\ $\square$ Corresponding author email: earmstrongmensah@gsu.edu
}

\section{ABSTRACT}

Access to safe drinking water and adequate sanitation are basic necessities of life, yet not everyone in the world is able to access these services, particularly people living in rural areas. Rural areas in Ghana, defined as communities with populations less than 5,000 people, and some rural areas in the United States (US), defined as non-metropolitan communities, experience water and sanitation-related issues to varying degrees. The purpose of the field study was to examine individual and community level issues related to sanitation, and water sources, water quality, treatment and management, water needs and water-related illness in Accra, Ghana, and to determine areas of similarities and differences with the US. Thus, study results are not generalizable to the entire population of Ghana. Given the short duration of the entire field study (three weeks) and the fact that most information on water and sanitation in the US is publicly-available, secondary data from various sources were used for the US comparison. Results from the study showed that $61.4 \%$ of study participants in the selected communities in Accra and $80.0 \%$ of Americans living in rural areas had access to safe water. Lack of access to toilet facilities was minimal in rural communities in both Ghana and the US.

Keywords: •Water $\bullet$ Sanitation $\bullet$ Water Quality $\bullet$ Ghana $\bullet$ Preventable Illnesses $\bullet$ Inequalities

Copyright (C) 2022 Willis et al. Published by Global Health and Education Projects, Inc. This is an open-access article distributed under the terms of the Creative Commons Attribution License CC BY 4.0.

\section{Introduction}

\section{I.I. Statement of the Problem}

Water and sanitation are basic necessities of life and crucial to the health and well-being of the human population, yet not everyone in the world has access to them. Globally, over 785 million people lack access to essential water services, and over 884 million people lack access to safe drinking water.' It is estimated that about $40 \%$ of the world's population lacks access to adequate sanitation facilities and thus, practice open defecation.'

Despite significant investments made by the government of Ghana and its development partners in water and sanitation infrastructure over the past 30 years, $10 \%$ of Ghanaians, especially those living in rural areas, still lack access to safe drinking water and $14 \%$ lack access to adequate sanitation facilities. ${ }^{2}$ Some reasons for this include broken-down facilities, 
water pollution, and rapid urbanization. The primary sources of water in rural communities in Ghana are private piped water systems, standpipes, boreholes with a handpump, hand-dug wells, and open water sources such as streams, rivers, lakes, and ponds. Some of these water sources are prone to environmental contamination.

Lack of access to safe water and adequate sanitation are risk factors for poor health outcomes. According to the World Bank, about 19,000 Ghanaians living in rural areas, including children under the age of 5, die from water and sanitationrelated diseases such as typhoid and diarrhea each year. ${ }^{3}$ Recognizing these issues, Member States of the United Nations, including Ghana and the US, adopted Millennium Development Goal 7 in 2000, and Sustainable Development Goal 6 in 2015, which seek to reduce the lack of global access to safe drinking water and adequate sanitation.

\section{I.2. Objectives}

The purpose of the field study was to examine individual and community level factors related to sanitation, water quality, water treatment and management, water needs and water-related illness in select rural communities in Accra, Ghana. Specifically, a field-based review of water and sanitation-related issues in rural Ghana were analyzed and compared with publicly available data in the US to determine areas of similarities and differences.

\section{Methods}

\section{I. Description of Activities}

As part of the three-week Georgia State University School of Public Health's Ghana Study Abroad Program, we participated in a virtual field study in the summer of 2021. The field study focused on three contemporary public health issues (water and sanitation, HIV, and women's health) and required students to participate in lectures, site visits, field trips and to write a field study report. For the field report aspect of the study, our team chose to focus on water and sanitation. Due to COVID-19 travel restrictions, we were unable to travel physically to Ghana. As a result, we had our in-country partner at the Suntreso Government Hospital located in
Kumasi, use an electronic questionnaire we created in Qualtrics to collect data on our behalf over a period of four weeks prior to the commencement of the three-week study abroad program. We pilot tested the questionnaire with our in-country partner for appropriateness, clarity, and ease of administration since the partner was to administer it. His feedback was used to revise and finalize the questionnaire.

\subsection{Setting}

The study focused on women and men living in selected rural communities in Accra. Individuals were qualified to participate in the study if they lived in any of the 20 rural communities selected for the study in Accra (Table I).

\subsection{Data Collection}

We used a cross-sectional mixed-method study design. Using the face-to-face questionnaire administration format, data were collected electronically using Qualtrics from IOI residents

\section{Table I: Selected Rural Communities and} Districts in Accra, Ghana

\begin{tabular}{ll}
\hline Community & District \\
\hline I.Ayikofi Otaten & Ga West \\
\hline 2. Samsam & Ga West \\
\hline 3. Kojo Ashong & Ga West \\
\hline 4.Ayikai Doblo & Ga West \\
\hline 5.Akwegyiri no. 2 & Ga West \\
\hline 6. Koteiman & Ga West \\
\hline 7. Kramoman & Ga West \\
\hline 8. Torkuse & Ga South \\
\hline 9. Kofi Kwei & Ga South \\
\hline 10.Agbledo Asuaba & Ga South \\
\hline II.Zingakope & Ga South \\
\hline 12. Bosuafise-Zoglo & Ga South \\
\hline 13. Obinfo Agumezekope & Ga South \\
\hline 14. Medie & Ga South \\
\hline 15. Nsuobri no. 2 & Ga South \\
\hline 16. Osuwem - Gbese & Shai-Osudoku \\
\hline 17. Osuwem - Estate & Shai-Osudoku \\
\hline 18.Asutsuare & Shai-Osudoku \\
\hline 19. Sege & Ada West \\
\hline 20. Kweiman (Ayimensah, & Lakwantanang-Madina \\
\hline Danfa, Otinibi) & \\
\hline
\end{tabular}


in 20 rural communities in 5 districts in Accra (Table I) using $\mathrm{Ga}$ (the predominant language spoken in Accra), Twi, or English, depending on the language spoken by the community member. Data were collected over four weeks. Prior to data collection, our in-country partner obtained consent from study participants and informed them of the confidentiality of information provided. The questionnaire comprised 20 questions covering seven domains: I) demographic information, 2) sanitation facilities, 3) sources of water, 4) water quality, 5) water treatment and management, 6) water needs, and 7) illness due to water. An average of five questionnaires were administered per community so as to collect data on diverse water sources.

\subsection{Data Cleaning and Analysis}

Quantitative and qualitative data collected were exported from Qualtrics to the Statistical Package for the Social Sciences (SPSS) version 26 for data analysis (IBM Corp. Released 2019. IBM SPSS Statistics for Windows, Version 26.0. Armonk, NY: IBM Corp). Prior to data analysis, all questionnaires were checked for completion, double entries, and inconsistencies. Quantitative data with missing values were excluded from calculations. Descriptive analysis was used to summarize the data. Qualitative data were analyzed manually using the thematic approach.

\subsection{Ethical Approval}

We worked with one of our community partners in Ghana to obtain institutional review board (IRB) approval from the Kwame Nkrumah University of Science and Technology prior to data collection.

\section{Findings}

\section{I. Demographic Information and Sanitation Facilities}

We found that $61.4 \%$ of study participants in the selected rural communities in Accra had access to safe water. ${ }^{4}$ However, a few lacked access to adequate sanitation facilities. Of the $10 \mathrm{I}$ participants surveyed, $45.4 \%$ had completed senior secondary school, $71.3 \%$ were married, and about $3.0 \%$ were widowed. Fifty-four percent of the study participants indicated that they use a ventilated improved pit latrine with a fly trap to meet their sanitation needs, and $84.0 \%$ said that they use private toilets.

\subsection{Sources of Water}

Overall, $27.0 \%$ of study participants in rural communities in Accra used water from a standpipe to wash their hands after using the toilet, $26.0 \%$ used a borehole with a handpump, $15.0 \%$ used a private piped water system, $14.0 \%$ used a hand-dug well without a pump, $13.0 \%$ used an open water source, and $5 \%$ used water from various sources including streams, rivers, or ponds (Table 2). Regarding water

Table 2: Study Participant-Reported Sources of Water for Handwashing, Bathing, Drinking, and Cooking

\begin{tabular}{|c|c|c|}
\hline Water source & $\begin{array}{l}\text { Sample } \\
\text { Size (N) }\end{array}$ & $\begin{array}{c}\text { Percentage } \\
(\%)\end{array}$ \\
\hline \multicolumn{3}{|l|}{ Hand washing } \\
\hline Hand-dug well & 14 & 14.0 \\
\hline Standpipe & 27 & 27.0 \\
\hline Borehole with a Pump & 26 & 26.0 \\
\hline Private Water system & 15 & 15.0 \\
\hline Open Water Source & 13 & 13.0 \\
\hline (stream, lake, river, pond) & 5 & 5.0 \\
\hline Other (canal or tanker) Missing & 0 & 0 \\
\hline \multicolumn{3}{|l|}{ Bathing } \\
\hline Hand-dug well & 14 & 13.9 \\
\hline Standpipe & 27 & 26.7 \\
\hline Borehole with a Pump & 27 & 26.7 \\
\hline Private Water System & 15 & 14.9 \\
\hline $\begin{array}{l}\text { Open Water Source } \\
\text { (stream, lake, river, pond) }\end{array}$ & 13 & 12.9 \\
\hline Other (canal or tanker) & 5 & 4.9 \\
\hline \multicolumn{3}{|l|}{ Drinking } \\
\hline Hand-dug well & 2 & 1.9 \\
\hline Standpipe & 9 & 8.9 \\
\hline Borehole with a Pump & 21 & 20.8 \\
\hline Private Water System & 4 & 4.0 \\
\hline Open Water Source & 4 & 4.0 \\
\hline (stream, lake, river, pond) & I & 1.0 \\
\hline \multicolumn{3}{|l|}{ Other (tanker) } \\
\hline Bottled/Packaged Water & 60 & 59.4 \\
\hline \multicolumn{3}{|l|}{ Cooking } \\
\hline Hand-dug well & 12 & 11.9 \\
\hline Standpipe & 29 & 28.7 \\
\hline Borehole with a Pump & 26 & 25.7 \\
\hline Private Water System & 15 & 14.9 \\
\hline $\begin{array}{l}\text { Open Water Source } \\
\text { (stream, lake, river, pond) }\end{array}$ & 13 & 12.9 \\
\hline Other (tanker) & 4 & 3.9 \\
\hline Bottled/Packaged Water & 2 & 2.0 \\
\hline
\end{tabular}


for bathing, an equal number of study participants (26.7\%) used water from a standpipe, or a borehole with a handpump, while $14.9 \%$ used water from a private piped water system. When it came to drinking water, $59.4 \%$ of study participants used bottled or packaged water, $20.8 \%$ used water from a borehole with a hand pump, and $9 \%$ used water from a standpipe. We found that $28.7 \%$ of study participants cooked with water from a standpipe, $25.7 \%$ with water from a borehole with a hand pump, and $14.9 \%$ with water from a private piped water system. (Table 2).

\subsection{Water Quality, Treatment, and Management}

The majority $(61.4 \%)$ of study participants in rural communities in Accra stated that they had good quality water. However, $38.9 \%$ reported that their water was not of good quality because it was salty (cited II times), difficult to wash with (cited 4 times), had algae in it (cited 3 times), was of poor quality after storage (cited 3 times), was dirty (cited 5 times), contained chemicals (cited I time), was used by animals (cited 3 times), and was bathed in by people (cited 2 times).

The majority of the study participants (67.3\%) reported that regardless of water source, they did not do anything to the water they collected prior to drinking. However, $90.6 \%$ of those who indicated that they did something to the water they collected, reported that they boiled it prior to drinking. Most study participants $(67.3 \%)$ reported paying for their water facility.

\subsection{Water Needs and Water-Related IIInesses}

Most of the study participants in rural communities in Accra (80.2\%) said they had access to sufficient drinking water. Over half $(54.5 \%)$ of study participants said that they had sufficient water for cooking and bathing and 10 reported that they had suffered from water-related illnesses such as skin rashes (cited 8 times), diarrhea (cited I time), and stomachache (cited I time) as a result of the water they drunk.

\section{Discussion and Implications for Policy and Practice}

This field study examined individual and community level factors related to sanitation, water quality, water treatment and management, water needs and water-related illness in 20 rural communities in Accra, Ghana. Given that majority of the students who participated in the study were native-born and residents of the US, our findings present a number of implications for public health policy and practice in the US and the host country which we discuss below.

\section{I. Sanitation Facilities}

We found that the percentage of study participants in the selected rural communities in Accra that engaged in open defecation due to the lack of access to sanitation facilities was lower $(2.9 \%)$ than the percentage for the whole of Accra (5.6\%)..$^{5}$ This may be due to the fact that we focused on only a few communities in Accra. Although comparatively lower, existing data show that less than $1.0 \%$ of residents in rural areas in the US engage in open defecation due to lack of access to sanitation facilities. ${ }^{6}$

\subsection{Sources of Water and Water Quality}

Study participants in the selected rural communities in Accra reported that they use bottled or packaged water to meet their drinking water needs. This we were told was primarily due to the presence of salt in some of the underground water sources. ${ }^{7}$ This finding is consistent with a study conducted by Archer et al. which showed that people in Ghana use bottled water when they believe that their drinking water is unsafe. ${ }^{8}$ Similarly, we found that about $33.0 \%$ of people living in rural communities in the US also drink bottled water because they consider bottled water safer and purer than water from piped systems, and also because they distrust their local government's ability to maintain water systems because of what happened in Flint, Michigan some years ago.?

Some residents of rural communities in the US also experience challenges associated with access to safe water. In 2017 , about $4.0 \%$ of Americans living in rural areas were drinking water from unsafe sources, and less than one percent lacked access to adequate sanitation facilities. ${ }^{6}$ Pollution from agricultural waste, shrinking populations, and the aging of rural water system infrastructure have been identified as sources of water pollution in the US. ${ }^{10}$ Similar to $61.4 \%$ of study participants in Ghana, about $77.0 \%$ of 
people living in rural communities in the US report that their water quality is excellent. However, some African American and Hispanic consumers report lower levels of satisfaction with the quality of water they have access to. ${ }^{4}$

\subsection{Water Treatment and Management}

According to study participants in Accra, international development agencies involved in the rural water supply and sanitation sector in Ghana usually test and treat water from the systems they provide. If test results show that the water is safe, nothing is done to the water. Unlike Accra, in the US, fluoride is always added to water from piped water supply systems from the onset, prior to distribution to consumers. In both Accra and the US, residents pay for their water supply.

\subsection{Water Needs and Water-Related IIInesses}

Access to safe water for bathing and cooking was an issue for some study participants in Accra because it meant they had to pay more money for water. This is however not an issue in rural communities in the US except among the homeless population." A few study participants in Accra said that their water sources did not make them sick. This was a bit of a surprise as some of the water sources used are not protected from animals and potential environmental contaminants.

\subsection{Strengths and Limitations}

There were a few limitations with the field study. Our in-country partner had to manage community expectations as some people thought her collecting data meant she was going to do something about their unimproved water sources. Our in-country partner addressed the expectation by explaining to community members that the effort was purely for academic purposes. Poor internet connectivity made it difficult for our in-country partner to collect data electronically in Qualtrics on some occasions. To address this challenge, she collected data manually and later entered it into Qualtrics when there was better connectivity. Since we focused on only select rural communities in Accra and used a convenient sample drawn from 20 rural areas, results from this field study cannot be generalized to the entire population of Ghana.

\subsection{Recommendation for Further Field Study for Students or Professionals}

For future field studies, it is recommended that community gatekeepers speak to community members prior to data collection, so there are no false hopes or expectations about the data being collected. It would also be good for students to collect data from other regions in Ghana to allow for a more detailed comparative and generalizable analysis.

\section{Compliance with Ethical Standards}

Conflicts of Interest: The authors declare no competing interests. Financial Disclosure: Nothing to declare. Funding/ Support: Publication support in part by the Georgia State University School of Public Health. Ethics Approval: IRB approval for the study was obtained from the Kwame Nkrumah University of Science and Technology in Ghana. Acknowledgments: We would like to acknowledge Professor Kodjo Senah of the University of Ghana, Professor Mawuli Dzodzomenyo of the University of Ghana, Mrs. Safuratu Muhammed Andani of the Ghana Community Water and Sanitation Agency, Mr. Patrick Apoya of SkyFox Limited in Ghana, Mr. Melvin Tagoe of the Ghana Community Water and Sanitation Agency, and Dr. Kim Ramsey-White of the Georgia State University,Atlanta, for their support during the field study. Disclaimer: None.

\section{Key Messages}

Water and sanitation are basic necessities of life, yet not everyone in the world has access to them.

Despite significant investments made by the government, many Ghanaians, especially those in rural areas, still lack access to safe water and adequate sanitation.

Access to safe water is also a public health issue in some rural areas in the US.

\section{References}

I. Akpakli D, Manyeh A, Akpakli J, et al. Determinants of access to improved sanitation facilities in rural districts of southern Ghana: evidence from Dodowa health and demographic surveillance site. BMC Res Notes. 2018; I I ( ):473. doi: I0. I I86/s I 3 104-0 I8-3572-6

2. Ghana. Safe Water Network. https://www. safewaternetwork.org/countries-regions/ghana. Published 2021. Accessed July 9, 2021.

3. Poor sanitation costs Ghana GHC420 million each year.The World Bank. https://www.worldbank.org/en/news/pressrelease/20 I 2/04/17/poor-sanitation-costs-ghana-ghc420million-each-year. Published April 17, 2012. Accessed July 9, 
2021.

4. Survey shows high confidence in U.S. tap water, lower satisfaction among Black, Hispanic respondents. American WaterWorks Association. https://www.awwa.org/AWWAArticles/survey-shows-high-confidence-in-us-tap-waterlower-satisfaction-among-black-hispanic-respondents. Published July 15, 2020. Accessed July 9, 2021.

5. Adzawla W, Alhassan $\mathrm{H}$, Jongare $\mathrm{A}$. Explaining the effects of socioeconomic and housing characteristics on the choice of toilet facilities among Ghanaian households. J Environ Public Health. 2020;2020: I-9.8.

6. Progress on household drinking water, sanitation, and hygiene 2000-2017: Special focus on inequalities. World Health Organization and United Nations Children's Fund. https:// www.who.int/water_sanitation_health/publications/jmp2019-full-report.pdf Published 2019.Accessed July 9, 2021.

7. Kortatsi B. Hydrochemical characterization of groundwater in the Accra plains of Ghana. Environ Geol. 2006;50(3):2993II. doi:10.1007/s00254-006-0206-4

8. Archer B, Tetteh A, Dsane-Nsor S. Evaluation of bottled water in the Ghanaian market. J Manag Inf Decis Sci. 2020;23(4): 244-253.

9. RosingerA, Herrick K,WutichA,Yoder J, Ogden C.Disparities in plain, tap and bottled water consumption among US adults: National Health and Nutrition Examination Survey (NHANES) 2007-2014. Public Health Nutr. 2018;21 (8): 1455|464. doi: 10.10I7/S|3689800|7004050
10. Condon M. Rural America's drinking water crisis. American Bar Association. https://www.americanbar.org/groups/ crsj/publications/human_rights_magazine_home/vol-44--no-2--housing/rural-america-s-drinking-water-crisis/. Published October 9, 2019. Accessed July 12, 2021.

II. Brooks C, Gortmaker S, Long M, Cradock A, Kenney E. Racial/ethnic and socioeconomic disparities in hydration status among US adults and the role of tap water and other beverage intake. Am J Public Health. 20 I7; 107(9): I387-1394. doi: 10.2105/AJPH.2017.303923

\section{PUBLISH IN THE}

International Journal of Translational Medical Reasearch and Public Health

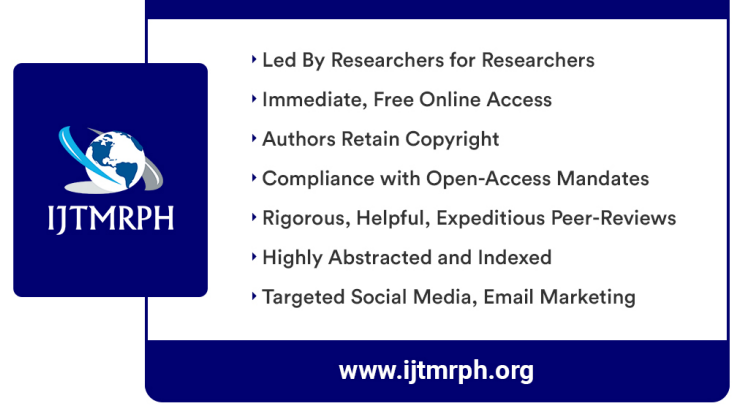

